\title{
The Role of Ultrasound Imaging in Ankle Impingement
}

\author{
RANIA ZEITOUN, M.D., F.R.C.R.*; LAMIAA I.A. METWALLY, M.D.* and MOHAMED EL-AZAB, M.D.** \\ The Department of Diagnostic and Interventional Radiology, Faculty of Medicine* and \\ The Department of Diagnostic Radiology, National Cancer Institute**, Cairo University, Egypt
}

\begin{abstract}
Background: Ankle impingement is a clinical condition of chronic and painful limited range of joint movement. It presents a significant clinical concern athletes and young population.

Aim of Study: To study the value of US in the diagnosis of soft tissue and bony ankle impingement, using combined plain radiography and MRI as a reference for diagnosis.

Patients and Methods: The study included 20 patients $(8$ male and 12 female), mean age: 35.1 years, suspected to have ankle impingement by clinical examination. The included patients underwent US ankle examination. The diagnosis of impingement was classified according to the anatomical compartments and categorized according to the underlying impinging factor as bony or soft tissue impingement. We calculated a $p$-value to evaluate the role of US in diagnosis of bone and soft tissue impingement.
\end{abstract}

Results: Eight patients had single compartment impingement and 12 patients (60\%) had multi-compartments impingement with a total number of 40 compartments impingement. The observed impingements were categorized into $22 \mathrm{soft}$ tissue and 18 bone impingements. Ultrasound could detect 11 out of 18 bone impingements ( $p$-value $=0.011)$ and 21 out of 22 soft tissue impingements $(p$-value $=0.005)$.

Conclusion: Ultrasound is a helpful diagnostic tool in cases of bone and soft tissue ankle impingement.

Key Words: Ankle impingement-Ankle ultrasound.

\section{Introduction}

ANKLE impingement is defined as entrapment of one of the anatomic structures in the ankle that leads to pain and decreased range of motion. Ankle impingement syndromes are now increasingly recognized as a significant cause of chronic ankle pain. The diagnosis of these conditions is of special importance in athletes and young populations,

Correspondence to: Dr. Rania Zeitoun, E-Mail: raniazeitoun@gmail.com. rania.zeitoun@kasralainy.edu.eg because of related morbidities and possible deformities [1-4].

Ankle impingement syndromes are described according the involved anatomical region of the ankle as anterior, anterolateral, anteromedial, posterior and posteromedial. According to the underlying impinging cause, ankle impingement can be either bony, soft tissue or a combination of both [2-7].

The diagnosis of ankle impingement is primarily a clinical diagnosis with imaging is needed to provide the supporting evidence of diagnosis and point to the causative impinging factor. Different imaging modalities, including plain radiography, Computed Tomography (CT), Ultrasonography (US) and Magnetic Resonance Imaging (MRI) can be used with variable strength and weakness relative to the limitations of each modality [2-7]. Magnetic resonance imaging is superior for detection of soft tissue abnormalities, while plain radiography and CT are superior for detection of bone abnormalities. Magnetic resonance imaging is considered by some as the modality of choice with successful interpretation of both bone and soft tissue (capsule, ligaments and synovium) abnormalities. Intra-articular contrast injection (arthrography) followed by CT or MR imaging has also been described as a helpful diagnostic tool allowing better distension and hence evaluation of ankle compartments and recesses [8-11].

There is a higher demand these days for US implementation in the diagnosis of various musculoskeletal pathologies and guided joints injection $[2,12-17]$. The purpose of our work is to study the value of US in the diagnosis of soft tissue and bony ankle impingement, using combined plain radiography and MRI as a reference for diagnosis. 


\section{Patients and Methods}

\section{Patients:}

The study is observational analytic, included 20 patients ( 8 male and 12 female), age range: 22 64 years, mean age: 35.1 years. The inclusion criteria are patients suspected to have ankle impingement by clinical examination and confirmed by combined review of plain X-ray and MRI. The patients were referred from Kasr Al-Ainy Hospital Outpatient Department, they underwent ankle US at the Radiology Department, Kasr Al-Ainy Hospital, Cairo University; during the time period: January to June 2019 . The study excluded cases with ankle surgery. The study has been approved by the "Ethical Committee of Faculty of Medicine, Cairo University", in compliance with Helsinki Declaration and all patients signed a formal concent.

\section{Imaging protocol:}

US examination: The used machine was Toshiba Ultrasound Aplio 500; Toshiba Medical, Japan, using the $18 \mathrm{MHz}$ linear probe. For each patient, 2D grey scale, color and power Doppler in different planes was done as well as dynamic examination. Scanning of the other ankle was done when needed to compare the symptomatic ankle to the contralateral normal side. Excess gel was used instead of the gel pad. The radiologist who performed the US examination was blinded to the plain radiography and MRI findings.

MRI: Was performed using: Philips Achieva; Philips Medical Systems, The Netherlands, (1.5 T). Ankle coil was used. Every patient lied supine with the ankle and foot in neutral position. No movement was allowed during examination by supporting the ankle using pads.

\section{Imaging interpretation:}

For each patient, the plain X-ray and MRI findings were reported independently by one musculoskeletal radiologist (10 years experience) and the US was done by another musculoskeletal radiologist (10 years experience). Each radiologist reported the patients' images while blinded to the other's findings. The combined plain X-ray and MRI findings were considered the reference for US findings. The diagnosis of impingement was classified according to the anatomical compartments into: Anterior, anterolateral, anteromedial, posterior and posteromedial. The impingement was categorized according to the underlying impinging factor as bony or soft tissue impingement. The results of US diagnosis were used to calculate a $p$-value.

\section{Statistics:}

Data were coded and entered using the statistical package SPSS (Statistical Package for the Social Sciences) Version 25. Data was summarized using mean, standard deviation, median, minimum and maximum in quantitative data and using frequency (count) and relative frequency (percentage) for categorical data. For comparing categorical data, Chi square $\left(\mathrm{X}^{2}\right)$ test was performed. Exact test was used instead when the expected frequency is less than 5. $p$-values less than 0.05 were considered as statistically significant.

\section{Results}

The study included 20 patients. The combined review of plain X-ray and MRI showed that 8 patients had impingement at single anatomical compartment while the rest $12(60 \%)$ had impingements at more than one compartment. The total number of compartments impingement was 40 . The observed impingements were categorized according to the underlying etiological factor into 18 bone Fig. (1) and 22 soft tissue Figs. $(2,3)$ impingements at their corresponding anatomical compartments (Table 1). The most commonly involved anatomical compartment is the posterior. The underlying bone and soft tissue impinging factors are listed in (Table 2).

For the included ankle impingement cases, US could detect 11 out of 18 bone impingements ( $p$ value $=0.011)$ and 21 out of 22 soft tissue impingements $(p$-value $=0.005)$.

Table (1): Bone and soft tissue impingements at different ankle compartments.

\begin{tabular}{ccc}
\hline & $\begin{array}{c}\text { Plain X-ray } \\
\text { \& MRI }\end{array}$ & US \\
\hline Bone impingement: & 9 & 6 \\
Posterior & 4 & 2 \\
Postero-medial & 3 & 2 \\
Antero-lateral & 2 & 1 \\
Anterior & 18 & 11 \\
Total & & \\
Soft tissue: & 7 & 7 \\
Posterior & 5 & 5 \\
Postero-medial & 7 & 7 \\
Antero-lateral & 2 & 1 \\
Anterior & 1 & 1 \\
Antero-medial & 22 & 21 \\
\hline Total & & \\
\hline
\end{tabular}



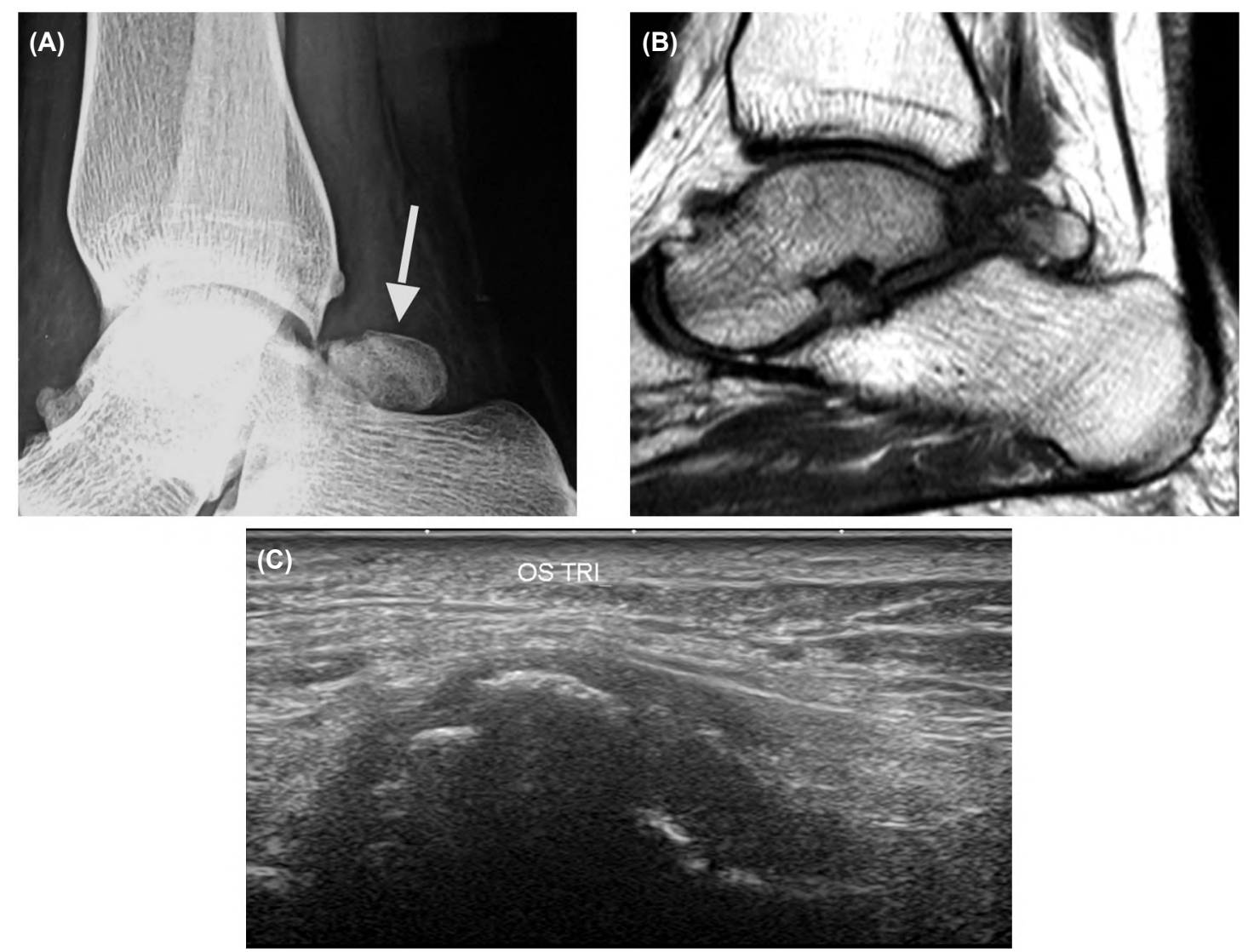

Fig. (1): Posterior bone impingement in a-22 year-old male patient, suffering from long standing posterior ankle pain and limited planter flexion. (A) Plain radiograph shows a large Os trigonum (arrow). (B) MRI Sagittal T1WI showing large Os trigonum and surrounding synovial thickening and effusion of hypointense signal. (C) US in longitudinal plane shows a large Os trigonum impinging the flexor hallucis longus tendon at the posterior ankle compartment.
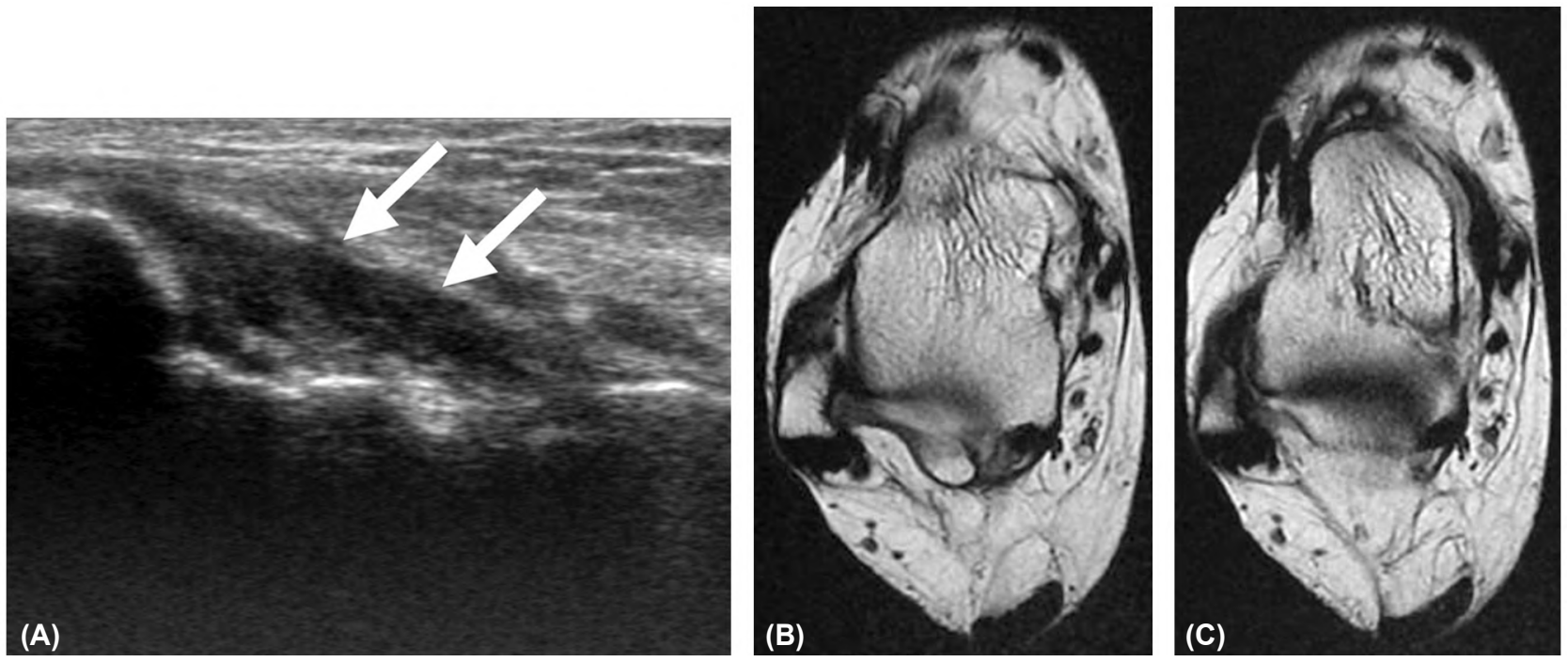

Fig. (2): Antero-lateral soft tissue impingement in a-25 year-old female patient complaining of persistent pain following inversion ankle injury from 6 months. (A) US in transverse plane shows thickened anterior talo-fibular ligament and heterogeneously increased echogenicity (arrows). (B and C) MRI axial T2WIs show remarkable thickening of the anterior talo-fibular ligament, with preserved ligaments attachment and continuity. 

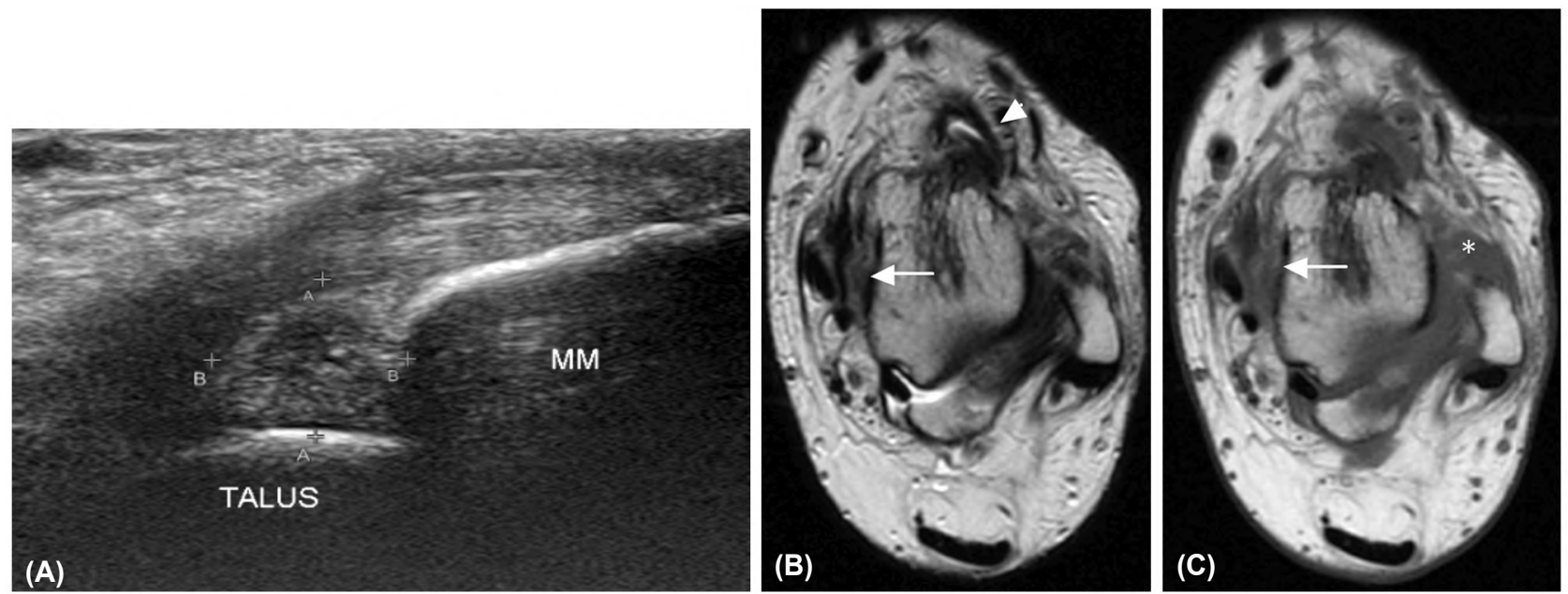

Fig. (3): Multiple compartments impingement in a-22 year-old male patient complaining of left ankle posterior and posteromedial pain with history of twist injury 10 years ago. (A) US image in oblique plane showing synovial soft tissue thickening in between the talus and medial malleolus. (B and C) MRI axial T2WIs and T1WIs showing synovial soft tissue thickening of hypointense signal deep to the tibiotalar ligament and tendons. The same images show anterior bone impingement by talar bone spurs and overlying synovial thickening and small ganglion cyst (short arrow). Anterolateral compartment soft tissue impingement (asrtix) by synovial soft tissue thickening at the anterolateral gutter.

Table (2): Causative factors of bone and soft tissue impingements.

Bone:

- Bone spurs

- Accessory bones

- Prominent Steida process

- Non united fracture

- Malunited fracture

Soft tissue

- Synovial: Thickening-proliferation-fibrosishemarthrosis

- Ligaments: Thickening-healed tear-chronic degeneration

- Ganglion cyst

\section{Discussion}

Ankle impingement is described as chronic painful limited range of joint movement. It is increasingly raised as a clinical condition of potential morbidity in young athletes. Most of the cases are secondary to trauma, which may be in the form of repetitive microtrauma or a memorable trauma incident. Trauma may result in a non-united or malunited fracture, ligament or capsule injury which later heal by fibrosis. On the other hand, impingement may be caused by developmental bone abnormalities like non united ossific centers (Os trigonum) or may be attributed to degenerative joint disease and bone spurs or may be secondary to a synovial pathology [2]

In our study, most (60\%) of the included patients had multi-compartmental impingement. There was a slight predominance of soft tissue impingement over bone impingement. In bone impingement cases, posterior compartment was the most commonly involved ankle compartment, while in soft tissue impingement, both posterior and anterolateral compartments were equally involved, followed by posteromedial compartment. The most common impinging factor in the presented cases was synovial abnormalities in soft tissue impingement and bone spurs in bone impingement.

Most of the reviewed literature emphasized the role of MRI and its superior soft tissue contrast resolution in ankle impingement, while fewer studies discussed US. We believe that US cannot replace MRI as a diagnostic tool, but being a widely available imaging modality, it can save time and cost and it allows dynamic imaging as well [18-20]

Our results showed that US is a good diagnostic tool in bone and soft tissue impingements with significant $p$-values 0.011 and 0.005 respectively. In other studies, US was successful in detection of $100 \%$ of soft tissue anterolateral and posteromedial impingement cases [13,21]. Ultrasound can also be helpful in detection of other abnormalities that may mimic symptoms of impingement or may even co-exist rendering treatment ineffective. These abnormalities may include tendinopathy, tenosynovitis, enthesitis, bone spurs.

The main limitation of our study is that our results ( $p$-value for US) are collectively for all the included ankle compartments. Studying the role of US for each anatomical compartment and including larger number of cases with addition of 
dynamic imaging is further planned for our next research work.

\section{Conclusion:}

Ultrasound is a helpful diagnostic tool in cases of bone and soft tissue ankle impingement.

\section{References}

1- UMANS H.: Ankle impingement syndromes. Semin. Musculoskelet. Radiol., Jun., 6 (2): 133-9, 2002.

2- PESQUER L., GUILLO S., MEYER P. and HAUGER O.: US in ankle impingement syndrome. J. Ultrasound., Jun., 17 (2): 89-97, 2014.

3- DONOVAN A. and ROSENBERG Z.S.: MRI of ankle and lateral hindfoot impingement syndromes. A.J.R. Am. J. Roentgenol., Sep., 195 (3): 595-604, 2010

4- RUSSO A., ZAPPIA M., REGINELLI A., CARFORA M., D'AGOSTO G.F., La PORTA M., et al.: Ankle impingement: A review of multimodality imaging approach. Musculoskelet Surg., Aug., 97 (Suppl 2): S161-8, 2013.

5- BERMAN Z., TAFUR M., AHMED S.S., HUANG B.K. and CHANG E.Y.: Ankle impingement syndromes: An imaging review. Br. J. Radiol., Feb., 90 (1070): 20160735 , 2017.

6- HOPPER M.A. and ROBINSON P.: Ankle impingement syndromes. Radiol. Clin. North Am., Nov., 46 (6): 957971, v, 2008.

7- DIMMICK S. and LINKLATER J.: Ankle impingement syndromes. Radiol. Clin. North Am., May, 51 (3): 479$510,2013$.

8- ROBINSON P., WHITE L.M., SALONEN D.C., DANIELS T.R. and OGILVIE-HARRIS D.: Anterolateral ankle impingement: $\mathrm{Mr}$ arthrographic assessment of the anterolateral recess. Radiology, Oct., 221 (1): 186-90, 2001.

9- COCHET H., PELÉ E., AMORETTI N., BRUNOT S., LAFENÊTRE O. and HAUGER O.: Anterolateral ankle impingement: Diagnostic performance of MDCT arthrography and sonography. A.J.R. Am. J. Roentgenol., Jun., 194 (6): 1575-80, 2010.

10- ROBINSON P., WHITE L.M.: Soft-tissue and osseous impingement syndromes of the ankle: Role of imaging in diagnosis and management. Radiogr. Rev. Publ. Radiol Soc. N. Am. Inc., Dec., 22 (6): 1457, 1469, 1471, 2002.
11-BUREAU N.J., CARDINAL E., HOBDEN R. and AUBIN B.: Posterior ankle impingement syndrome: MR imaging findings in seven patients. Radiology, May, 215 (2): 497 503,2000

12- ROBINSON P. and BOLLEN S.R.: Posterior ankle impingement in professional soccer players: Effectiveness of sonographically guided therapy. A.J.R. Am. J. Roentgenol., Jul., 187 (1): W53-58, 2006.

13- MESSIOU C., ROBINSON P., O'CONNOR P.J. and GRAINGER A.: Subacute posteromedial impingement of the ankle in athletes: MR imaging evaluation and ultrasound guided therapy. Skeletal. Radiol., Feb., 35 (2): 88-94, 2006.

14- YABLON C.M.: Ultrasound-guided interventions of the foot and ankle. Semin. Musculoskelet. Radiol., Feb., 17 (1): 60-8, 2013

15- SOFKA C.M.: Posterior ankle impingement: Clarification and confirmation of the pathoanatomy. HSS J. Musculoskelet J. Hosp. Spec. Surg., Feb., 6 (1): 99-101, 2010.

16- BATTAGLIA P.J., CRAIG K. and KETTNER N.W.: Ultrasonography in the Assessment of Lateral Ankle Ligament Injury, Instability, and Anterior Ankle Impingement: A Diagnostic Case Report. J. Chiropr. Med., Dec., 14 (4): 265-9, 2015.

17- DATIR A. and CONNELL D.: Imaging of impingement lesions in the ankle. Top Magn. Reson. Imaging TMRI. Feb., 21 (1): 15-23, 2010.

18- ALVES T., DONG Q., JACOBSON J., YABLON C. and GANDIKOTA G.: Normal and Injured Ankle Ligaments on Ultrasonography With Magnetic Resonance Imaging Correlation. J. Ultrasound Med. Off J. Am. Inst. Ultrasound Med., Feb., 38 (2): 513-28, 2019.

19-FESSELL D.P., VANDERSCHUEREN G.M., JACOBSON J.A., CEULEMANS R.Y., PRASAD A., CRAIG J.G., et al.: US of the ankle: Technique, anatomy, and diagnosis of pathologic conditions. Radiogr. Rev. Publ. Radiol. Soc. N. Am. Inc., Apr., 18 (2): 325-40, 1998.

20- MASCIOCCHI C., CATALUCCI A. and BARILE A.: Ankle impingement syndromes. Eur. J. Radiol., May, 27 (Suppl 1): S70-73, 1998.

21- McCARTHY C.L., WILSON D.J. and COLTMAN T.P.: Anterolateral ankle impingement: Findings and diagnostic accuracy with ultrasound imaging. Skeletal Radiol., Mar., 37 (3): 209-16, 2008 


\section{دور التصوير بالموجات فوق الصوتية فى تشخيص حالات إختتاق الكاحل}

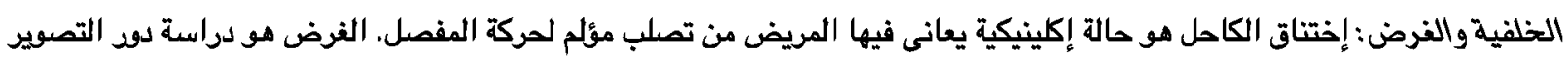

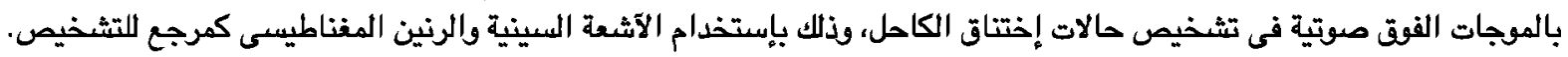

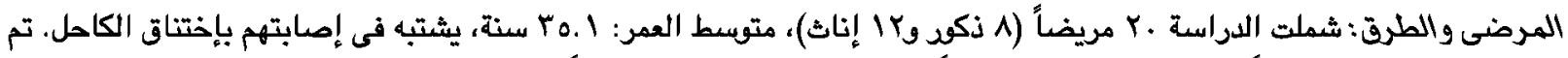

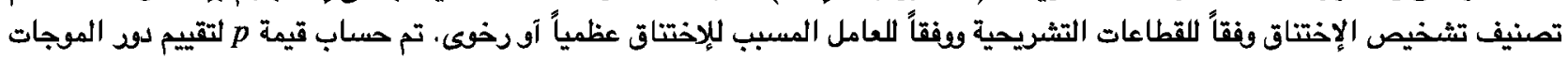
الفوق صوتية فى تشخيص إختناق الكاحل.

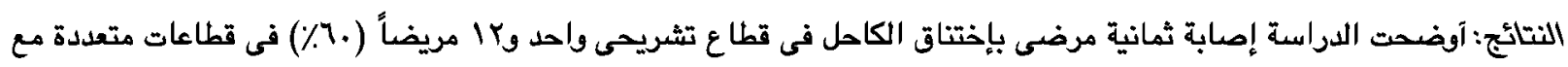

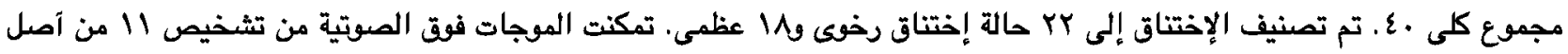

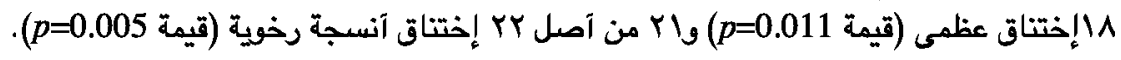
الإستتاج: الموجات فوق الصوتية آداة تثخيصية مفيدة فى حالات إختناق الكاحل. 